\title{
What is the best way of intensively treating patients with type 2 diabetes?
}

\author{
M Fisher \\ Consultant Physician, Glasgow Royal Infirmary, Glasgow, UK
}

TITLE Intensive blood glucose control and vascular outcomes in patients with type 2 diabetes

\section{AUTHORS ADVANCE Collaborative Group}

JOURNAL N Engl J Med 2008; 358: 2560-72. doi:I0.1056/NEJMoa0802987

DECLARATION OF INTERESTS The author took part in the ADVANCE trial and was a member of the Collaborative Group.

Published online December 2009

\author{
Correspondence to $\mathbf{M}$ Fisher, \\ Wards 4 \& 5, Glasgow Royal \\ Infirmary, 84 Castle Street, \\ Glasgow G4 OSF, UK \\ tel. +44 (0) I4I 2 I I 4 I82 \\ e-mail miles.fisher@ggc.scot.nhs.uk
}

\section{SUMMARY}

The ADVANCE trial was a large, randomised, multicentre, factorial trial conducted in 20 countries to assess the effects of intensive versus standard glucose control on microvascular and macrovascular outcomes in people with type 2 diabetes. Another part of the study was completed earlier and showed that the addition of perindopril plus indapamide reduced major vascular events and death, regardless of initial blood pressure.'

A total of II,I40 patients with type 2 diabetes were randomised to standard control or to intensive control with a target glycated haemoglobin $\left(\mathrm{HbA}_{\mathrm{lc}}\right)$ concentration of less than $6.5 \%$. In the intensive control group, first-line therapy was with modified release gliclazide, a sulphonylurea, with the addition of other drugs including insulin as required to reach target.

After a median follow-up of five years there was little change in $\mathrm{HbA}_{\mathrm{lc}}$ in the standard group at $7.3 \%$. The median $\mathrm{HbA}_{\mathrm{lc}}$ in the intensive control group was $6.5 \%$, and this level was not reached until four years into the study. Intensive control significantly reduced the primary endpoint, which was a composite of microvascular and macrovascular events, and further analysis showed that this was primarily because of a reduction in nephropathy, with no significant increase or decrease in macrovascular events, cardiovascular death or total mortality.

Few side effects were noted in the intensive control group. There was little weight gain, and although severe hypoglycaemia (requiring help from another person) was increased, this was uncommon.

\section{REFERENCES}

I Patel A, ADVANCE Collaborative Group. Effects of a fixed combination of perindopril and indapamide on macrovascular and microvascular outcomes in patients with type 2 diabetes mellitus (the ADVANCE trial): a randomised controlled trial. Lancet 2007; 370:829-40. doi:10.1016/S0I40-6736(07)6I303-8

\section{OPINION}

The ADVANCE trial demonstrated that intensive blood glucose control reduced microvascular but not macrovascular events over a five-year period. This was immensely reassuring as the ACCORD study, ${ }^{2}$ which was published in the same edition of the New England Journal of Medicine, was stopped prematurely after 3.5 years of follow-up because of an increase in total mortality in patients assigned to receive intensive glucose-lowering therapy. This included an increase in unexpected or presumed cardiovascular deaths.

While there are some similarities between the ADVANCE and ACCORD trials, there are also clear differences in study design. The ADVANCE trial adopted a slow but steady approach to the tightening of glucose control, insulin was added at a rather late stage, and as a consequence it took four years to reach target $\mathrm{HbA}_{\mathrm{lc}}$ levels. By contrast, in the ACCORD trial, treatments were added rapidly, including insulin, so that the median $\mathrm{HbA}_{\mathrm{lc}}$ of $6.4 \%$ in the intensive group was reached in four months. It should be noted that the target for the intensive group in ACCORD was an $\mathrm{HbA}_{\mathrm{lc}}$ of $6 \%$, but this was not attained.

Secondly, in ACCORD excessive weight gain and hypoglycaemia requiring assistance were common in the intensive group. The ACCORD authors stated that statistical analysis did not identify severe hypoglycaemia as a cause for the excess mortality, but in my opinion this is the likely explanation.

As diabetic nephropathy remains a common cause for chronic renal failure, intensive control of blood glucose using the ADVANCE regimen and $\mathrm{HbA}_{\mathrm{lc}}$ target is clinically appropriate.

2 Action to Control Cardiovascular Risk in Diabetes Study Group. Effects of intensive glucose lowering in type 2 diabetes. $N$ Engl J Med 2008; 358:2545-59. doi:I0.I056/NEJMoa0802743 